\title{
A Material Model for the Orthotropic and Viscous Behavior of Separators in Lithium-Ion Batteries under High Mechanical Loads
}

\author{
Marian Bulla ${ }^{1, *(\mathbb{D})}$, Stefan Kolling ${ }^{2} \mathbb{D}$ and Elham Sahraei ${ }^{3,4}(\mathbb{D}$ \\ 1 Altair Engineering GmbH, Josef-Lammerting-Allee 10, 50933 Cologne, Germany \\ 2 Institute of Mechanics and Materials, Technische Hochschule Mittelhessen, Wiesenstr. 14, \\ 35390 Giessen, Germany; stefan.kolling@me.thm.de \\ 3 Electric Vehicle Safety Lab (EVSL), Temple University, Philadelphia, PA 19122, USA; \\ elham.sahraei@temple.edu \\ 4 Impact and Crashworthiness Lab, Massachusetts Institute of Technology, Cambridge, MA 02139, USA \\ * Correspondence: bulla@altair.com; Tel.: +49-160-96367668
}

Citation: Bulla, M.; Kolling, S.; Sahraei, E. A Material Model for the Orthotropic and Viscous Behavior of Separators in Lithium-Ion Batteries under High Mechanical Loads. Energies 2021, 14, 4585. https:// doi.org/10.3390/en14154585

Academic Editor: Carlos Miguel Costa

Received: 29 June 2021

Accepted: 23 July 2021

Published: 29 July 2021

Publisher's Note: MDPI stays neutral with regard to jurisdictional claims in published maps and institutional affiliations.

Copyright: (c) 2021 by the authors. Licensee MDPI, Basel, Switzerland. This article is an open access article distributed under the terms and conditions of the Creative Commons Attribution (CC BY) license (https:/ / creativecommons.org/licenses/by/ $4.0 /)$.

\begin{abstract}
The present study is focused on the development of a material model where the orthotropicvisco-elastic and orthotropic-visco-plastic mechanical behavior of a polymeric material is considered. The increasing need to reduce the climate-damaging exhaust gases in the automotive industry leads to an increasing usage of electric powered drive systems using Lithium-ion (Li-ion) batteries. For the safety and crashworthiness investigations, a deeper understanding of the mechanical behavior under high and dynamic loads is needed. In order to prevent internal short circuits and thermal runaways within a Li-ion battery, the separator plays a crucial role. Based on results of material tests, a novel material model for finite element analysis (FEA) is developed using the explicit solver Altair Radioss. Based on this model, the visco-elastic-orthotropic, as well as the visco-plastic-orthotropic, behavior until failure can be modeled. Finally, a FE simulation model of the separator material is performed, using the results of different tensile tests conducted at three different velocities, $0.1 \mathrm{~mm} \cdot \mathrm{s}^{-1}, 1.0 \mathrm{~mm} \cdot \mathrm{s}^{-1}$ and $10.0 \mathrm{~mm} \cdot \mathrm{s}^{-1}$ and different orientations of the specimen. The purpose is to predict the anisotropic, rate-dependent stiffness behavior of separator materials in order to improve FE simulations of the mechanical behavior of batteries and therefore reduce the development time of electrically powered vehicles and consumer goods. The present novel material model in combination with a well-suited failure criterion, which considers the different states of stress and anisotropic-visco-dependent failure limits, can be applied for crashworthiness FE analysis. The model succeeded in predicting anisotropic, visco-elastic orthotropic and visco-plastic orthotropic stiffness behavior up to failure.
\end{abstract}

Keywords: polyethylene separator; visco-elasticity; visco-plasticity; elasto-plasticity; orthotropy; material model; finite element model; safety; crashworthiness

\section{Introduction}

Increasing efficiency, defined as energy consumption relative to the distance travelled, is considered a core development goal of the automotive industry. Customer demands for vehicles with larger mobility range in combination with legal requirements for climate protection by limiting $\mathrm{CO}_{2}$ emissions are the motivation for increasing the efficiency of electric vehicles. In addition to the ecological motivation, economic factors are a major incentive for vehicle manufacturers to focus on the reduction in the development time of their vehicles by using high fidelity computational simulation tools such as finite element analysis. Product development to raise battery performance of portable electronic devices such as laptops or mobile phones also benefits from an increased accuracy of FEA results [1,2]. To achieve this goal, more precise FE models are required to describe the mechanical behavior of all involved materials under high mechanical loads. Recent developments, especially in the 
automotive industry, with focus on the electrification require precise prediction of how Li-ion cells respond to high mechanical load cases, due to misuse or crash events. Here, understanding the properties of the polymeric separator layer, maintaining a physical barrier between anodes and cathodes plays an important role. Therefore, knowing its mechanical behavior, especially in the nonlinear domain, is essential.

In the past, the determination of material properties for plastics was mainly limited to the determination of elastic parameters and yield strength. These characteristic values were determined almost exclusively under quasi-static loading at one defined orientation. Typical characteristic values for FE modeling of plastics are available, for example, in the Computer Aided Material Preselection by Uniform Standards (CAMPUS) database [3]. Since the largest part of energy in crash processes is dissipated by plastic deformation, the material models, used for crashworthiness analysis, must also be able to describe the plastic material behavior accurately. The determination of the plastic material behavior is difficult for many plastics, since engineering strains with more than $100 \%$ value can occur under tensile loading. In addition, it is possible to have inhomogeneous distribution of strains in such plastic parts, which is also referred to as strain localization [4]. In the tensile test, this strain localization is noticeable by a constriction of the specimen. Standard strain measurement methods, such as strain gauges or extensometers, cannot consider these localizations. Therefore, the displacement at the clamping of the specimen is often used for strain measurement in the entire specimen. This determination of the strain distribution over the free gripping length of the specimen is also proposed in the standard for determining the tensile properties of plastics, ISO EN 527 [5]. However, this procedure can lead to considerable errors in the strain measurement as local strain overshoots are not detected. A reliable determination of the stress-strain curve, which represents the physical material behavior, which is necessary as a basis for the development of material models, is thus not readily available of such materials [6,7].

A further difficulty arises from the widely varying material behavior of different plastics [8]. The behavior of polymers is affected by many factors, e.g., moisture, temperature and others. In addition, polymers are sensitive to the rate of loading. An increase in the strain rate often results in a decrease in the ductility of the polymer. In contrast, the modulus and the yield or tensile strength increase with increasing loading rate [9]. Many authors have examined the influence of temperature and strain rate on the material behavior of polymers. Walley and Field [10] performed tests at room temperature over strain rates ranging from $10^{-2} \mathrm{~s}^{-1}$ to $10^{4} \mathrm{~s}^{-1}$. Carnella [11] provided rate-dependent tests at high strain rates under tension and compression.

Therefore, several problems arise in the development of material models for the numerical representation of thermoplastic components under dynamic and high load cases. Neither in commercial simulation programs nor in the literature do material models exist that have been developed specifically for the crash simulation of thermoplastic components. For this reason, material models developed for metallic materials are often used in industrial applications to illustrate the dynamic material behavior of thermoplastics. This includes, above all, the von Mises plasticity models. However, this material model is not suitable for mapping the mechanical behavior of thermoplastics and, as shown in [12] and this leads to incorrect results. The reason for this lies in two aspects, which are important for a precise mechanical response prediction: (1) viscose effects in the elastic domain and (2) anisotropic material hardening in the plastic domain. Deeper investigation of anisotropic behavior is performed in Pfeiffer et al. [13].

In this work, the focus is on the modeling of the separator material used in Li-ion batteries using time explicit method of nonlinear dynamic FEM. Figure 1 shows the multiscale view of a Panasonic 18650AF cell used in electric cars as well as in notebooks and other consumer goods showing the cell cross section and the multilayered structure inside that, including electrodes and the separator. Within this work, a novel material model is developed, which considers the visco-elastic-orthotropic as well as the visco-plastic-orthotropic (strain rate dependent) behavior for modeling of the separator. 
In addition to a suited failure model [14,15], the material stiffens, and the damage and fracture of a high dynamic mechanical load can be predicted. In Bulla et al. [16], a failure model is proposed, which considers the state of stress as well as the strain-rate effect based on the tests of a PE separator.

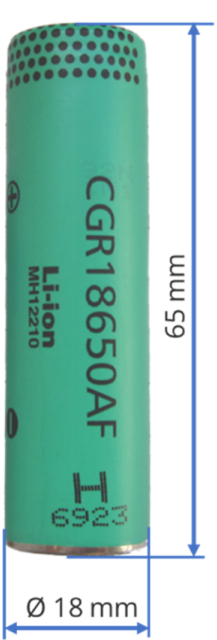

(a)

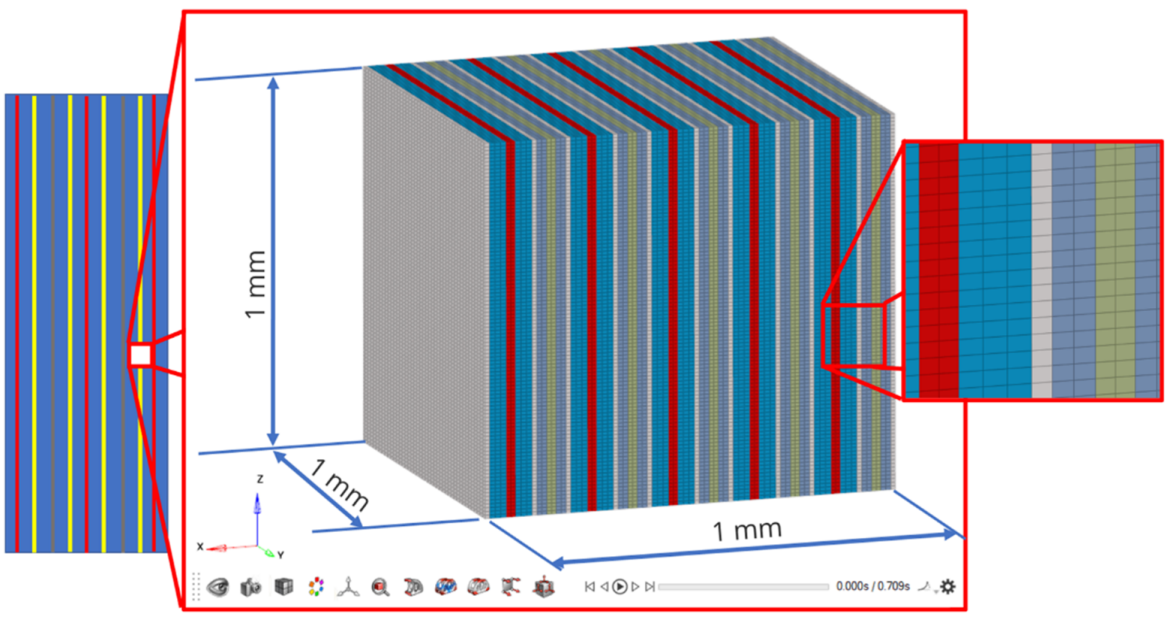

(c) (d)

Figure 1. Panasonic CGR18650AF Li-Ion cell: (a) real photo and (b) schematic cut-view, (c) Finite-Element-mesh using an $1 \times 1 \times 1 \mathrm{~mm}$ representative volume, $(\mathrm{d})$ detailed view of the $3 \mathrm{~d}$ hexahedron elements with an average element size of $0.01 \times 0.01 \times 0.01 \mathrm{~mm}$ showing the separator layer in white.

\section{Separator Materials and Methods}

The investigated commercial polymeric separator was provided to us from a battery manufacturing company. The exact chemical composition of the materials used in these samples was not specified. The separators had the porosity of 36-46\% [17].

In this study, the mechanical properties of the specimen were studied by conducting tensile tests on small strips cut out in 2 perpendicular spatial directions corresponding to machined direction (MD) and transversal direction (TD) of the separator samples. Figure 2 shows the experimental setup which was used for performing the tensile tests. Each specimen with dimensions of $12 \times 60 \times 0.025 \mathrm{~mm}$ was glued at each end to metal specimen holders which led to a free test length of $36 \mathrm{~mm}$. The specimens were marked with a gray pattern to enable digital image correlation (DIC), as shown in Figure 3a,b. The 3D ARAMIS system from GOM (GOM GmbH, Schmitzstraße 2, 38122 Braunschweig, Germany) was used for analysis of the strain field, shown in Figure 3c,d. Each test was repeated 5 times to ensure repeatability. Three different tension velocities were used for testing: $0.1 \mathrm{~mm} \cdot \mathrm{s}^{-1}$, $1 \mathrm{~mm} \cdot \mathrm{s}^{-1}$ and $10 \mathrm{~mm} \cdot \mathrm{s}^{-1}$ corresponding to strain rates $0.002778 \mathrm{~s}^{-1}, 0.02778 \mathrm{~s}^{-1}$, and $0.2778 \mathrm{~s}^{-1}$.

Figure 3 shows one specimen before and after testing. The recording frequency for the force and displacement measurements ranged from $2 \mathrm{~Hz}$ for the slowest tension velocity up to $40 \mathrm{~Hz}$ for the fastest ones.

The measured elongation in MD direction is in the range of 10-19 $\mathrm{mm}$, which results in $27-53 \%$ total strain. Figure 4 shows the engineering stress vs. engineering strain curves for the three tested velocities in MD. The Young's moduli are computed using the initial slope. Within this work, the statistical R-squared value (coefficient of determination) is used for the fitted regression line, starting with the first 2 measuring points. When the adjusted R-squared value drops below a defined threshold, we use the previous fit line as the Young's modulus. After failure, the specimen retained almost all its extension, which indicates a low relaxation. In conclusion, the material exhibits high plasticity and low elasticity behavior. Localization of strain occurs close to the center and proceeds to one of the fixed ends, where final rupture occurs. 


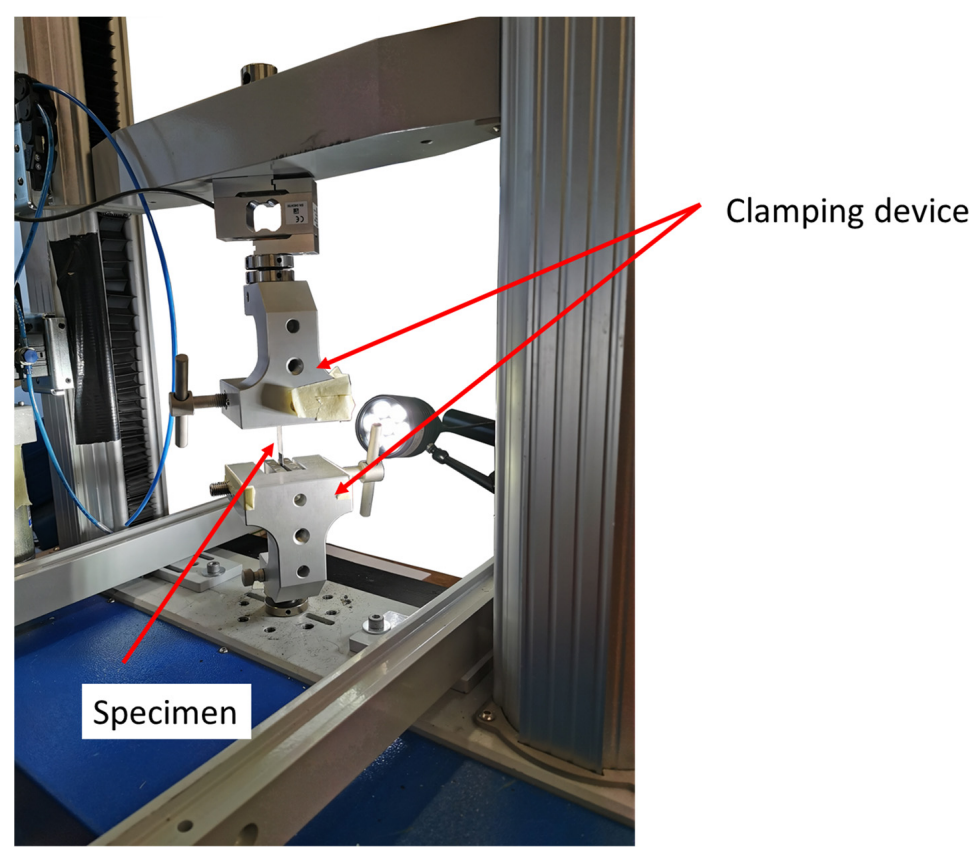

Figure 2. Experimental setup for the tension tests on the PE isolator specimen.

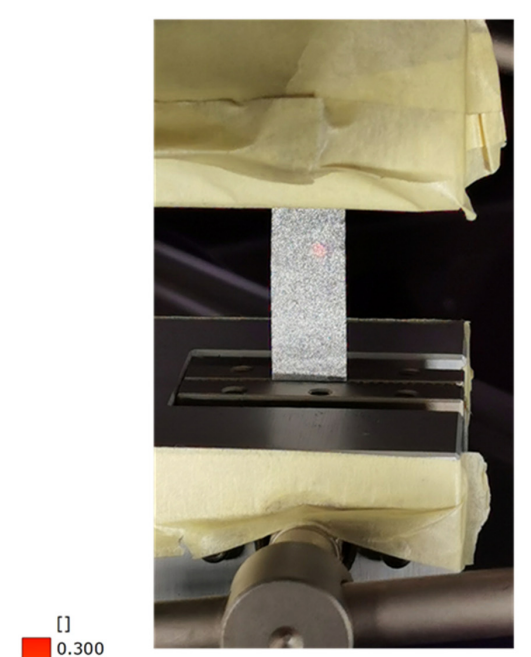

(a)

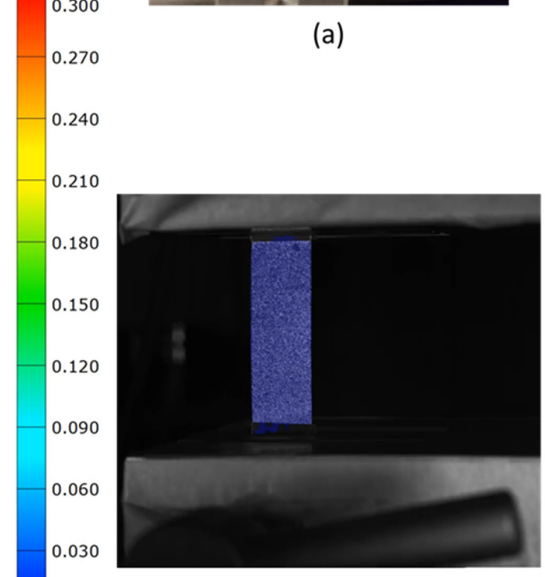

(c)

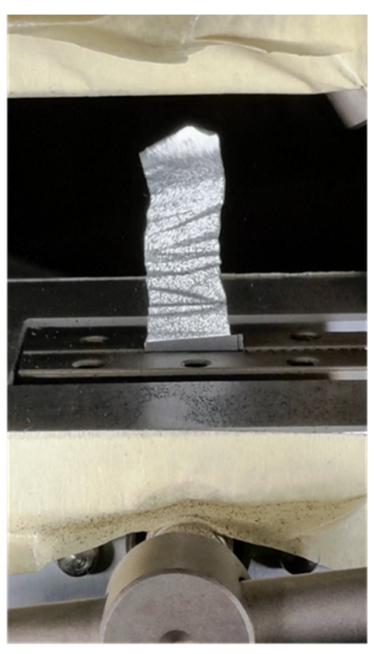

(b)

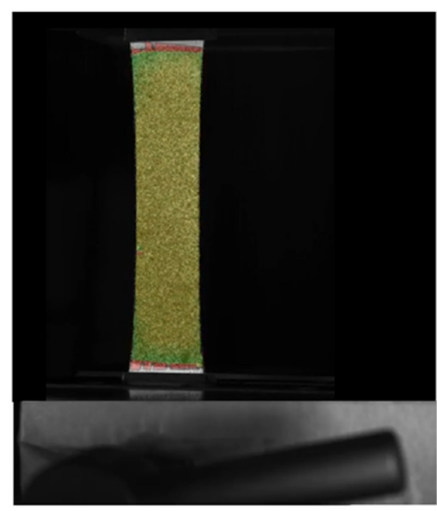

(d)

Figure 3. Set-up of prepared specimens in MD before the test (a) and at the end of the test, after failure (b). Specimen using DIC measurement at the beginning of the test (c) and at the end of the test, briefly before failure (d), showing the inhomogeneous strain field distribution withing the specimen. 


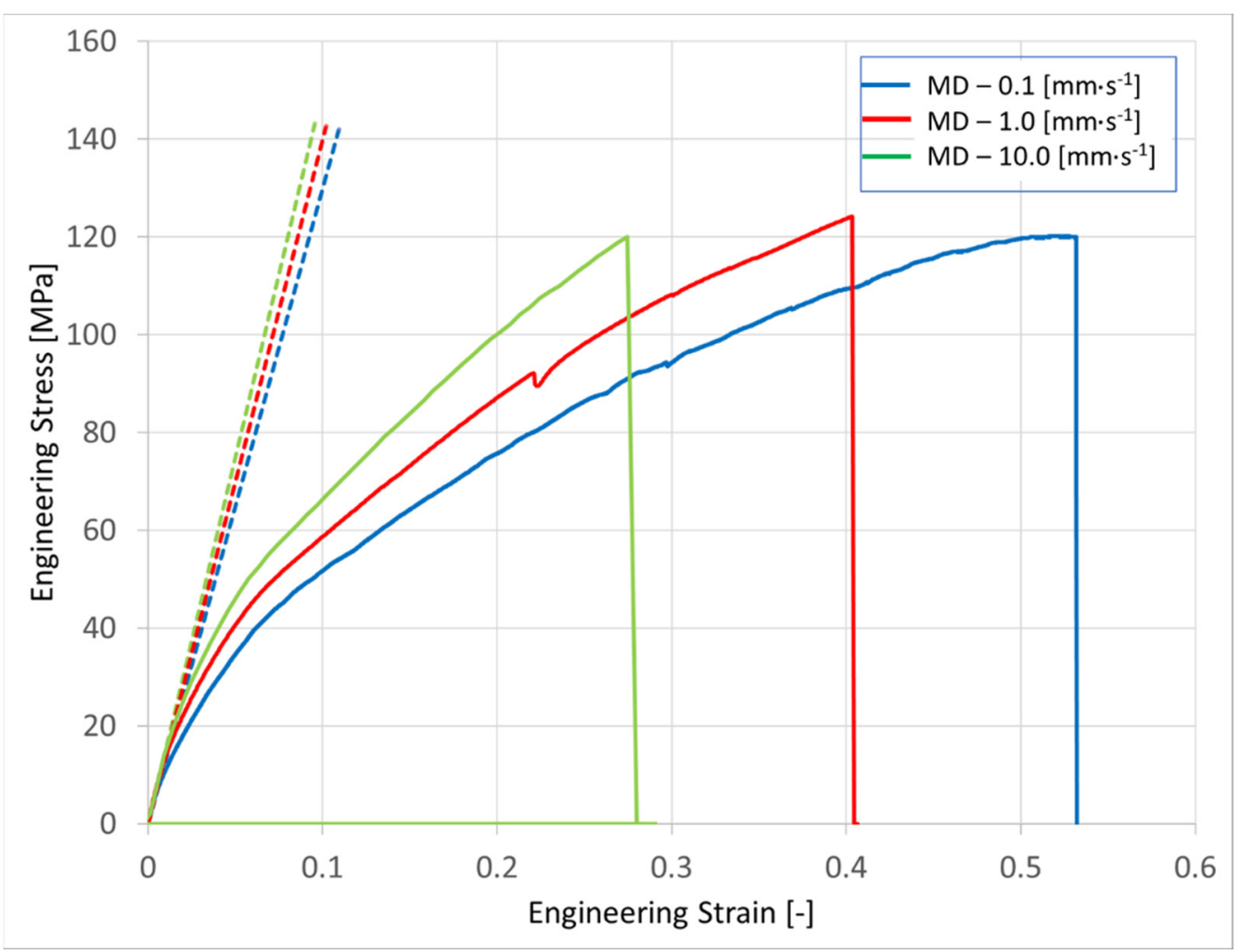

Figure 4. Tested engineering stress vs. strain curves in machine direction $\left(\mathrm{MD}=0^{\circ}\right)$, at three different velocities with the corresponding Young's moduli (dashed lines).

The measured elongation in TD direction was in the range of 40-53 mm, which results in $111-147 \%$ total strain. Figure 5 shows the engineering stress vs. strain curves for all three tested velocities in TD. The Young's moduli are computed using the initial slope as shown in Figure 6, which shows a cutout (indicated with the red-dotted rectangle in Figure 5).

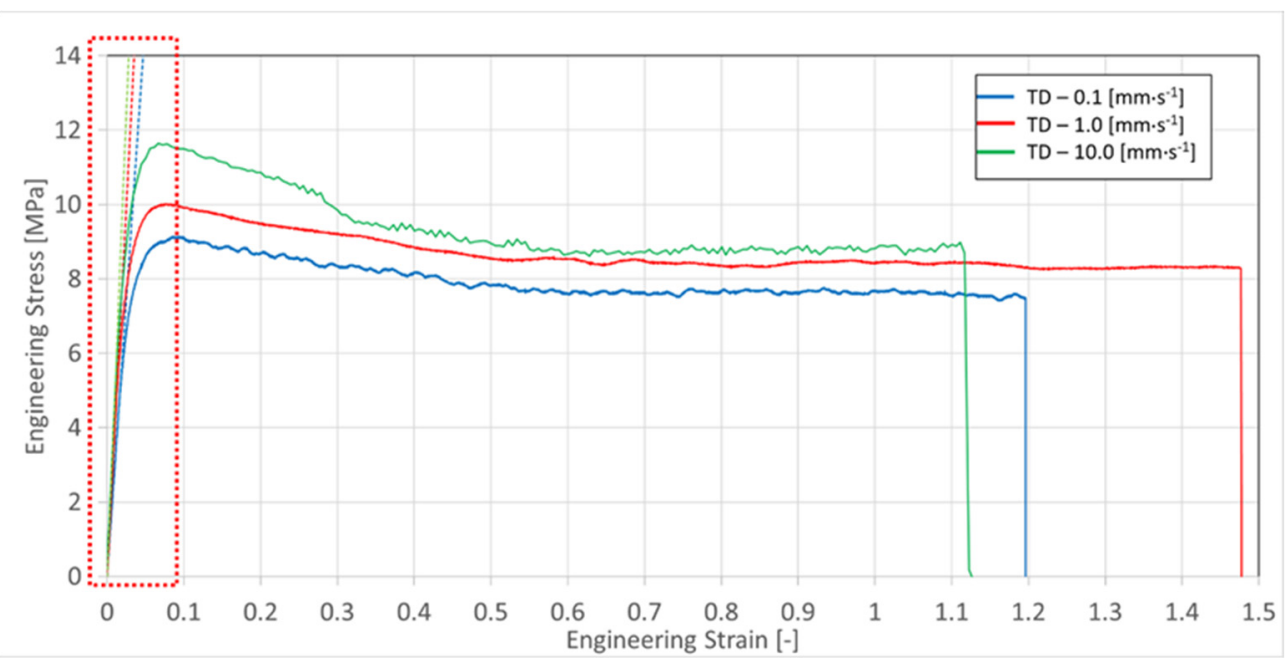

Figure 5. Tested engineering stress vs. strain curves in transverse direction $\left(\mathrm{TD}=90^{\circ}\right)$, at three different velocities with the corresponding Young's moduli (dashed lines) (dotted rectangle indicates the zoomed area). 


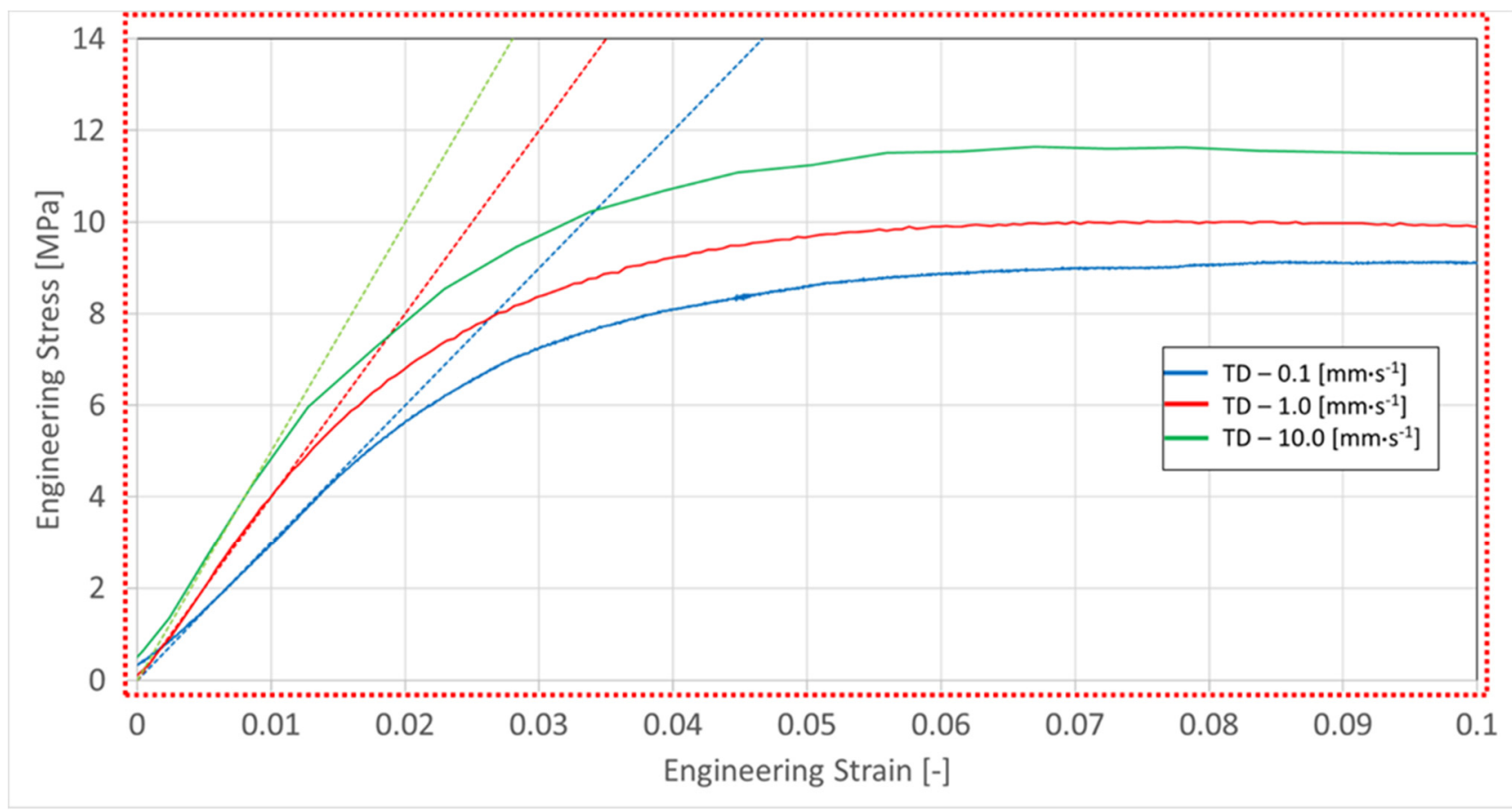

Figure 6. Detailed view of engineering stress vs. strain curves in TD direction $\left(\mathrm{TD}=90^{\circ}\right)$, at three different velocities with the corresponding Young's moduli (dashed lines).

Table 1 shows the estimated Young's moduli over the nominal strain rates (based on the used tension velocities). The values for the diagonal direction $\mathrm{DD}\left(=45^{\circ}\right)$ were obtained from Sahraei [17].

Table 1. Young's moduli dependent on orientation and engineering strain rate.

\begin{tabular}{cccc}
\hline Orientation (Degree) & $\dot{\boldsymbol{\varepsilon}}_{\mathbf{1}} \mathbf{=} \mathbf{0 . 0 0 2 7 7 8}\left(\mathrm{s}^{\mathbf{- 1}}\right)$ & $\dot{\boldsymbol{\varepsilon}}_{\mathbf{2}}=\mathbf{0 . 0 2 7 7 8}\left(\mathrm{s}^{\mathbf{1}}\right)$ & $\dot{\varepsilon}_{\mathbf{3}}=\mathbf{0 . 2 7 7 8}\left(\mathbf{s}^{\mathbf{1}}\right)$ \\
\hline 0 & $1300 \mathrm{MPa}$ & $1400 \mathrm{MPa}$ & $1500 \mathrm{MPa}$ \\
45 & $800 \mathrm{MPa}$ & $900 \mathrm{MPa}$ & $950 \mathrm{MPa}$ \\
90 & $300 \mathrm{MPa}$ & $400 \mathrm{MPa}$ & $500 \mathrm{MPa}$ \\
\hline
\end{tabular}

\section{Modeling and Results}

\subsection{Viscosity in Elastic Region}

Hereinafter the denotation of a matrix is defined as

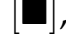

and of a vector as

$\{\boldsymbol{\square}\}$.

The viscosity effect is easily treated by explicit solvers because of the usage the equation of motion and solving for unknown values without the need of inverting the entire model:

$$
[M]\left\{\ddot{x}_{n}\right\}+[C]\left\{\dot{x}_{n}\right\}+[K]\left\{x_{n}\right\}=\left\{F_{\text {ext }}\left(t_{n}\right)\right\},
$$

where:

$$
\begin{aligned}
& {[M]=\text { Mass matrix }(\mathrm{kg}),} \\
& {[C]=\text { Damping matrix }\left(\mathrm{kg} \cdot \mathrm{m} \cdot \mathrm{s}^{-1}\right),} \\
& {[K]=\text { Stiffness matrix }\left(\mathrm{N} \cdot \mathrm{m}^{-1}\right),} \\
& \left\{\ddot{x}_{n}\right\}=\text { Acceleration vector }\left(\mathrm{m} \cdot \mathrm{s}^{-2}\right), \\
& \left\{\dot{x}_{n}\right\}=\text { Velocity vector }\left(\mathrm{m} \cdot \mathrm{s}^{-1}\right), \\
& \left\{x_{n}\right\}=\text { Displacement vector }(\mathrm{m}), \\
& \left\{F_{\text {ext }}\left(t_{n}\right)\right\}=\text { External force }(\mathrm{N}) .
\end{aligned}
$$


Due to the usage of the small strain formulation, where the stress increment is integrated at each time step and considering a stiffness that depends on the local strain rate in individual time steps, the integration schema-which solves the equation of motion in the time domain-leads to high oscillations of the total strain rates. Figure 7a shows considerable strain rate oscillations within the specimen during loading in the elastic domain. To reduce these oscillations, several approaches are used by commercial solvers [18-20].

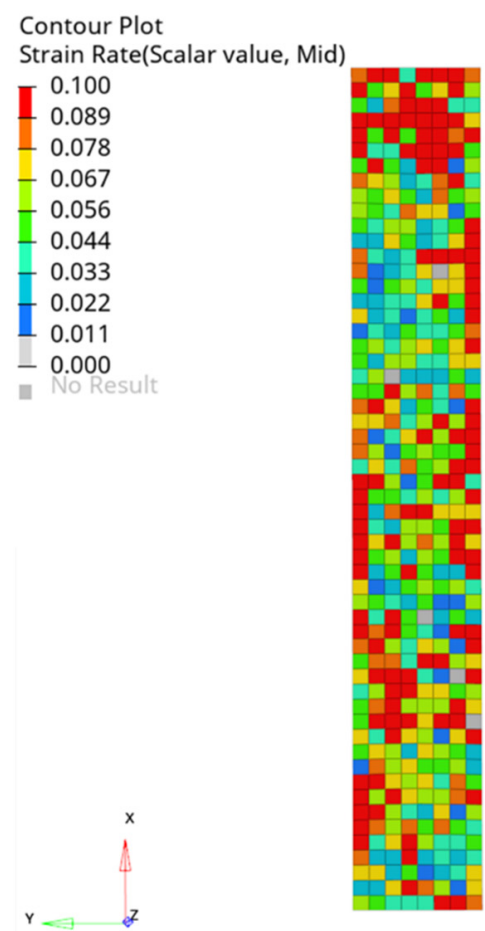

(a)
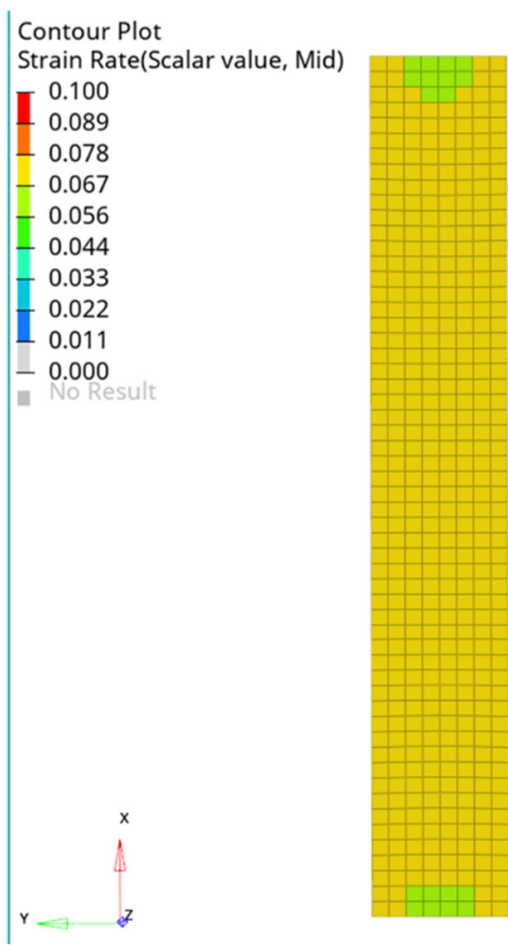

(b)

Figure 7. Visualization of strain rates within a tensile test specimen in the elastic domain. Unfiltered (a) and filtered (b) using the exponential moving average filter.

The approach chosen here is to apply an exponential moving average filter [21] to the strain rate as a time series filter that removes high frequency oscillations:

$$
\dot{\varepsilon}_{n}^{\text {average }}=\alpha_{E M A} \cdot \dot{\varepsilon}_{n-1}^{\text {average }}+\left(1-\alpha_{E M A}\right) \cdot \dot{\varepsilon}_{n},
$$

where:

$$
\begin{aligned}
& \dot{\varepsilon}_{n}^{\text {average }}=\text { Filtered actual strain rate }\left(\mathrm{s}^{-1}\right), \\
& \dot{\varepsilon}_{n-1}^{\text {average }}=\text { Filtered previous strain rate }\left(\mathrm{s}^{-1}\right), \\
& \dot{\varepsilon}_{n}=\text { Actual (not filtered) strain rate }\left(\mathrm{s}^{-1}\right), \\
& \alpha_{E M A}=\text { Exponential moving filter value }(-) .
\end{aligned}
$$

With the $\alpha_{E M A}$ parameter it is possible to control the response of the filter. If $\alpha_{E M A}=0$, no filtering is applied. Values close to 1 apply a strong low-pass filter. Figure $7 \mathrm{~b}$ shows the result of applying the strain rate filtering. It leads to a smoother strain rate distribution and more realistic behavior within the FE model. The strain rate filtering plays an important role in explicit time integration.

\subsection{Plasticity}

In the novel developed visco-elastic-plastic model, the true-stress vs. true-plasticstrain curves must be derived from the tested engineering-stress vs. engineering-strain curves. For the calculation of the plasticity curves in the MD direction, the approach based on Swift-Voce interpolation, described by Bulla [16], is used. However, the TD 
behavior is showing a much higher plasticity range beyond $100 \%$ strain. Figure 8 shows one representative engineering stress vs. engineering strain curve close to $120 \%$ total strain before the material fractures (green curve). For usage in an elasto-plastic material model, the parametrization for the engineering stress vs. engineering strain curve must be modified further. The true stress vs. true strain curve (Figure 8: red curve) is derived and then the elastic portion of the strain is subtracted from the total strain, using the linear strain-stress relation corresponding to the strain rate, dependent Young's modulus (Figure 6: dashed lines).

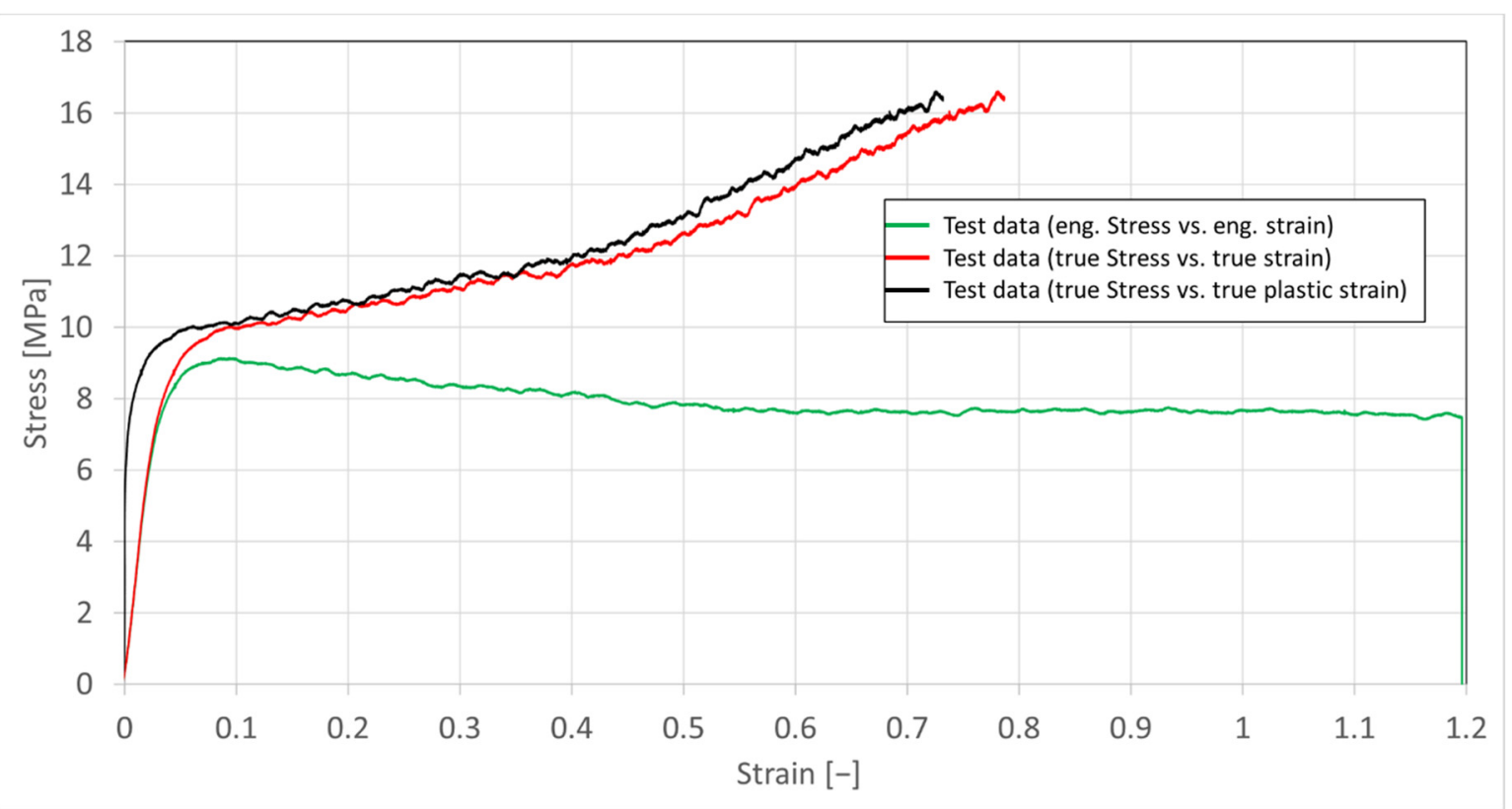

Figure 8. Preparation of the TD test curve from engineering stress vs. engineering strain (green curve), to true stress vs. true strain (red curve) to the true stress vs. true plastic strain (black curve).

Due to the need for values beyond the curve, derived from testing, it is necessary to extrapolate the true stress vs. true plastic strain curve. Based on the work of G'Sell et al. [22] who tested such high ductile polymer materials, the parameter identification is carried out using the modified equation:

$$
\sigma_{\text {yield }}=A+B \cdot\left(1-\exp \left(-C \cdot \bar{\varepsilon}_{p l .}\right)\right) \cdot\left(1+D \cdot \bar{\varepsilon}_{p l .}+F \cdot \bar{\varepsilon}_{p l .}^{2}\right)
$$

where:

$A=$ initial yield stress parameter $(\mathrm{MPa})$;

$B=$ hardening coefficient $(\mathrm{MPa})$;

$C=$ hardening plastic strain coefficient $(-)$

$D=2$ nd hardening plastic strain coefficient $(-)$;

$F=3$ rd hardening plastic strain coefficient $(-)$;

$\bar{\varepsilon}_{p l .}=$ equivalent plastic strain (-).

Table 2 shows the identified parameter used for the hardening curve, based on G'Sell equation.

Table 2. Parameter list obtained for the G'Sell hardening curve.

\begin{tabular}{ccccc}
\hline $\mathbf{A}(\mathbf{M P a})$ & $\mathbf{B}(\mathbf{M P a})$ & $\mathbf{C}(-)$ & $\mathbf{D}(-)$ & $\mathbf{F}(-)$ \\
\hline 0.005826 & 0.00422 & 77.76 & 0.09992 & 2.803 \\
\hline
\end{tabular}


Figure 9 shows very good agreement between the true stress vs. true plastic strain curves obtained from real test data (black curve) and the calculated hardening curve based on G'Sell's equation.

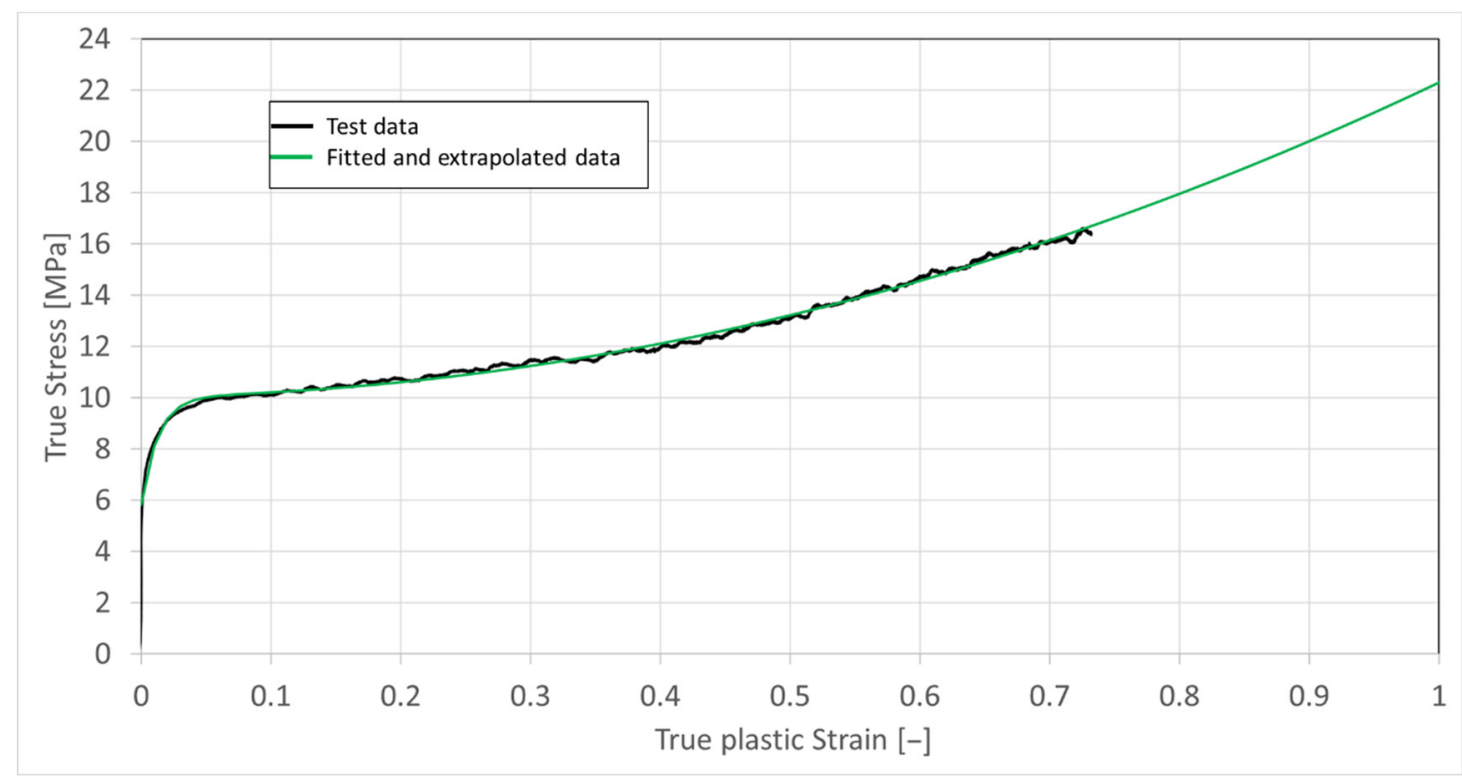

Figure 9. Hardening curve from real test (black curve) vs. calculated curve based on G'Sell's equation.

Within the further FEA analysis, the G'Sell-based hardening curve will be used for the TD behavior. Figure 10 shows parametrized hardening curves resulting from test data for different strain rates.

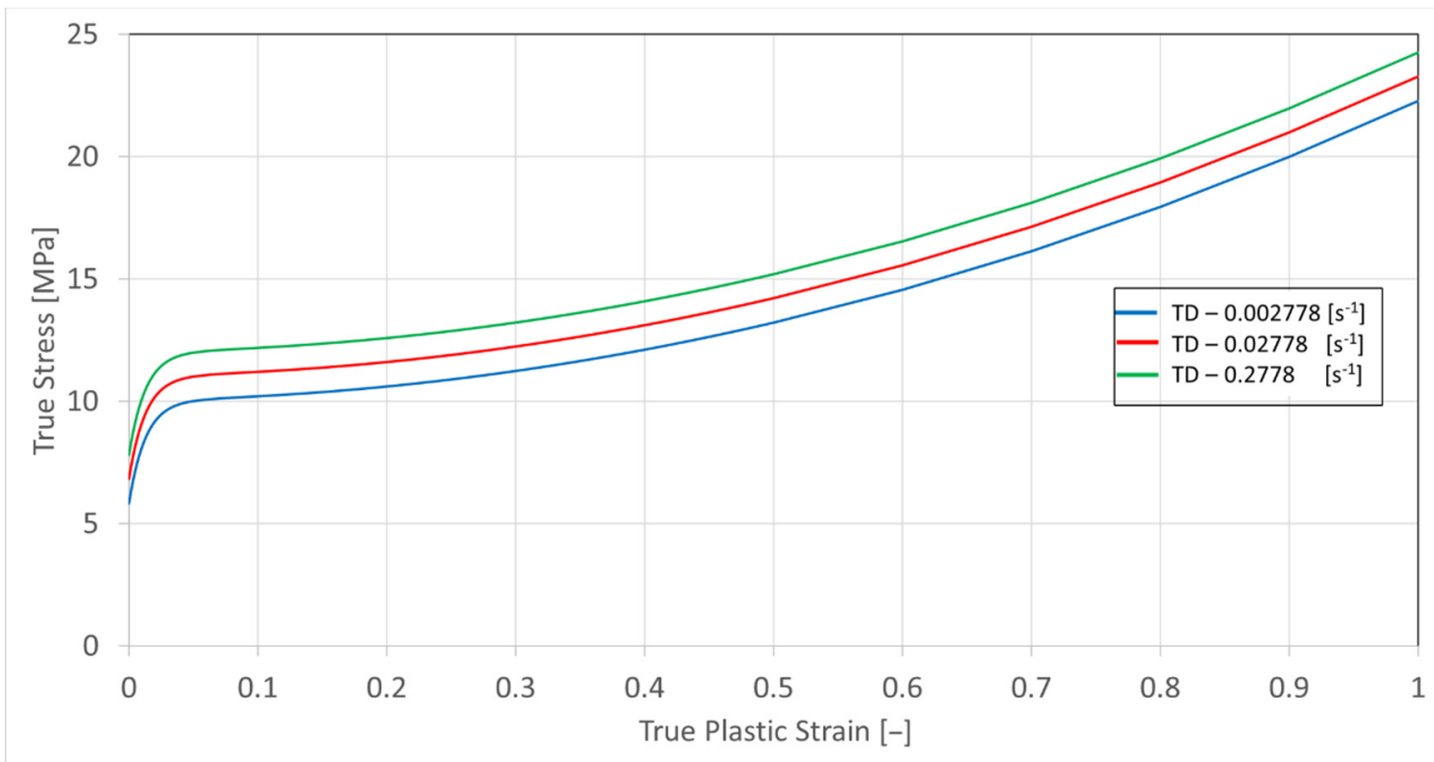

Figure 10. Fitted parametrized hardening curves resulting from test data for different strain rates in TD.

\subsection{Stability Investigation}

In the explicit FEA, the numerical stability plays an important role, since the numerical method is unstable if the timestep is above a critical timestep [23,24]. Another instability results from the material behavior. This material instability is investigated further since the tested separator material shows a large strain in the TD direction. 
In real tests with metallic materials, the engineering stress vs. engineering strain curve shows monotonic increase in stress with the increase in strain, starting with the slope of the Young's modulus. When approaching plastic deformation, the stress still increases, but with decreasing slope, until a maximum stress value is reached. Then, the measured stress starts to decrease. At this point of maximal stress, localization occurs, where a certain area continues plastic deformation without an increase in tension force. This important point is so called the necking point. For metals, the material instability is reached, and the material starts to damage and soften until final separation and failure will occur.

In the MD, the specimens reach their terminal strain shortly after the maximum stress is reached. With a well calibrated failure criterium, the finite elements, where this point is reached, will be deleted from further calculation.

In the TD of the tested material, the strain increases significantly after reaching the maximum stress value, without fracture. Therefore, the stability will be investigated more thoroughly. Inspired by the Drucker stability condition [25], which is widely used in hyper-elastic material models [26], the slope of the stress vs. strain curve will be analyzed. Using the true strain:

$$
\varepsilon_{\text {true }}=\int_{L_{0}}^{L_{1}} \frac{d L}{L}=\ln \frac{L_{1}}{L_{0}}=\ln \frac{L_{0}+\Delta L}{L_{0}}=\ln \left(1+\frac{\Delta L}{L_{0}}\right)=\ln \left(1+\varepsilon_{\text {eng }}\right)
$$

where:

$$
\begin{aligned}
& \varepsilon_{\text {eng }}=\text { engineering strain }(-) ; \\
& \varepsilon_{\text {true }}=\text { true strain }(-) ; \\
& L_{0}=\text { initial length }(\mathrm{mm}) ; \\
& L_{1}=\text { final length }(\mathrm{mm}) ; \\
& L=\text { measured Length }(\mathrm{mm}) ; \\
& \Delta L=\text { relative displacement }(\mathrm{mm}) \text { of the parallel length }
\end{aligned}
$$

and the true stress:

$$
\sigma_{\text {true }}=\frac{F}{S}=\frac{F \cdot L}{S \cdot L}=\frac{F \cdot L}{S_{0} \cdot L_{0}}=\sigma_{\text {eng }} \cdot e^{\varepsilon_{\text {true }}}=\sigma_{\text {eng }} \cdot\left(1+\varepsilon_{\text {eng }}\right),
$$

where:

$$
\begin{aligned}
& \sigma_{\text {true }}=\text { true stress }(\mathrm{MPa}) ; \\
& F=\text { measured force }(\mathrm{N}) ; \\
& S_{0}=\text { initial cross section }\left(\mathrm{mm}^{2}\right) ; \\
& S=\text { actual cross section }\left(\mathrm{mm}^{2}\right) \text { of the parallel length. }
\end{aligned}
$$

The assumption of constant volume is made due to the lack of measurement of volume change, because of the small thickness of the separator material. The extension of this work, including consideration of the volume change during the test, is the topic of ongoing work and will be the subject of future investigation. Assuming a stable behavior of a material with a positive slope in the engineering stress-strain relationship and isochoric behavior in plastic region, the limit is reached where the slope becomes zero:

$$
\frac{d \sigma_{\text {eng }}}{d \varepsilon_{\text {eng }}}=0
$$

This indicates the necking point. Proceeding with the slope in the true stress vs. true strain domain, used in the elasto-plastic material models:

$$
\frac{d \sigma_{\text {true }}}{d \varepsilon_{\text {true }}}=\frac{d \sigma_{\text {eng }} \cdot\left(1+\varepsilon_{\text {eng }}\right)+\sigma_{\text {eng }} \cdot d \varepsilon_{\text {eng }}}{\frac{1}{\left(1+\varepsilon_{\text {eng }}\right)} \cdot d \varepsilon_{\text {eng }}}=\frac{\left(1+\varepsilon_{\text {eng }}\right)^{2} \cdot d \sigma_{\text {eng }}}{d \varepsilon_{\text {eng }}}+\frac{\left(1+\varepsilon_{\text {eng }}\right) \cdot \sigma_{\text {eng }} \cdot d \varepsilon_{\text {eng }}}{d \varepsilon_{\text {eng }}},
$$


we obtain as a condition for the necking point:

$$
\frac{d \sigma_{\text {true }}}{d \varepsilon_{\text {true }}}=\sigma_{\text {true }}
$$

Figure 11 shows the true stress vs. true plastic strain and the first derivative in the same chart. According to Equation (8), the material instability occurs when the 1st derivative of the true stress vs. true strain curve equals the true stress value, which is the first crossing point. This corresponds to the maximum stress in the engineering stress vs. engineering strain diagram.

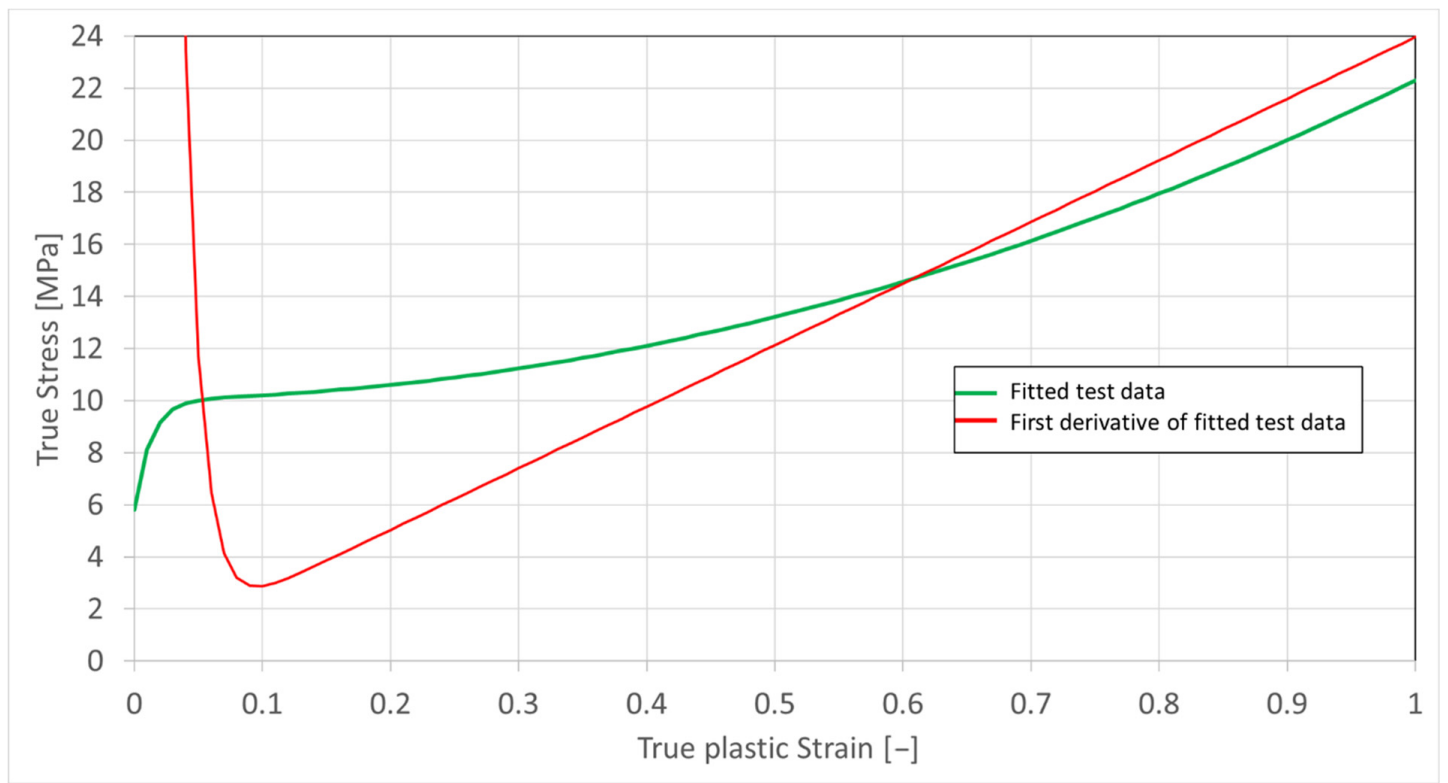

Figure 11. Extrapolated, fitted hardening curve in TD (green curve) and its 1st derivative, indicating the material stability range (red curve).

From this point, the first derivative is below the true stress vs. true plastic strain curve. This indicates an unstable material behavior. Proceeding further with the elongation up to a strain value of approximately 0.6 , the derivative crosses again the true stress vs. true strain curve and continues above this curve. This indicates a stabilization of the material due to potential orientation of the molecular chains in the loading direction.

A similar effect is observed in real tests in TD direction. Figure 12 sows two examples in TD, showing the localization through the rest of the specimen (a) or a localization in a certain area with a second localization occurring while proceeding with the tension test (b).
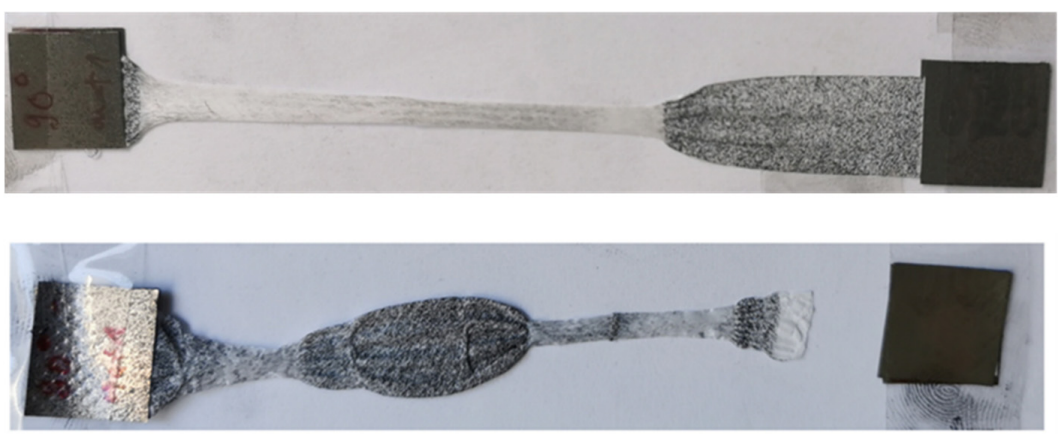

(b)

Figure 12. Test results TD showing a continuous localization starting close to the center of the specimen and proceeding towards one end (a) and a second localization started at the other end during the loading phase (b). 


\subsection{Material Modeling}

In a recent work, a nonlinear visco-elastic-orthotropic and visco-plastic-orthotropic material model was developed, based on the investigation of the PE material used as separator in Li-Ion batteries. In recent publications and commercial FEA products and solvers, there exists several material models to model the behavior of polymers [27-29].

Within the nonlinear and crashworthiness FEA models, used by the automotive and other industries, the by far most used material model is based on elasto-visco-plasticity, using the Von Mises plasticity formulation [30]. This is due to the fact that the user can easily obtain the necessary values to fit the material model by using results from various performed tensile tests. Another very important advantage of this model is based on the efficiency and performance in huge FE models, which lead to its wide usage in industrial environments [9].

Therefore, the Von Mises plasticity model was chosen as a basis and enhancements were implemented to handle the visco-elastic and orthotropic behavior of the PE separator.

Material modeling starts with the description of the isotropic, elastic behavior, which is based on Hooke's law:

$$
\{\sigma\}=[D]\{\varepsilon\},
$$

where:

$\{\sigma\}=2$ nd order stress tensor (MPa);

$[D]=4$ th order elasticity tensor $(\mathrm{MPa})$;

$\{\varepsilon\}=2$ nd order strain tensor $(-)$.

The elasticity tensor $[E]$ may be written in Voigt's notation as $6 \times 6$ matrix

$$
[D]=\frac{E}{(1+v)(1-2 v)}\left[\begin{array}{cccccc}
1-v & v & v & 0 & 0 & 0 \\
& 1-v & v & 0 & 0 & 0 \\
& & 1-v & 0 & 0 & 0 \\
& & & \frac{1-2 v}{2} & 0 & 0 \\
& \text { Symmetry } & & & \frac{1-2 v}{2} & 0 \\
& & & & & \frac{1-2 v}{2}
\end{array}\right],
$$

where:

$E=$ Young's modulus $(\mathrm{MPa})$;

$v=$ Poisson's ratio $(-)$.

Now, the Young's modulus $E$ will be replaced by the filtered, orthotropic, strainrate dependent Young's modulus $E(\dot{\varepsilon})$ interpolated nonlinearly between the three tested directions: MD, TD, DD (see Table 1).

For the nonlinear interpolation, between the three orthotropic directions, the cosineinterpolation function is used, as described by Bulla [16].

With the assumption of no sudden changes in the orthotropy of neighboring elements, the same method is applied to the Von Mises plastic potential:

$$
f\left(J_{2}, k\right)=\sqrt{3 J_{2}}-k=0,
$$

where:

$$
\begin{aligned}
& f=\text { Flow potential (MPa); } \\
& J_{2}=\text { deviatoric stress tensor (MPa); } \\
& k=\text { yield stress obtained from the uniaxial tension test }(\mathrm{MPa}) .
\end{aligned}
$$

We obtain the 2nd deviatoric stress invariant, using Einstein's notation:

$$
J_{2}=\frac{1}{2} S_{i j} S_{i j},
$$


with the additive decomposition of the stress tensor, the deviatoric stress is computed using:

$$
S_{i j}=\sigma_{i j}-\frac{1}{3} I_{1} \delta_{i j}
$$

where:

$$
\begin{aligned}
& S_{i j}=\text { deviatoric stress tensor }(\mathrm{MPa}) ; \\
& \sigma_{i j}=\text { Cauchy stress tensor }(\mathrm{MPa}) ; \\
& \delta_{i j}=\text { Kronecker delta }(-) .
\end{aligned}
$$

With:

$$
I_{1}=\sigma_{k k}
$$

where:

$I_{1}=1$ st invariant on the stress tensor (MPa).

Using a similar approach for viscosity and orthotropy, as used in the elastic region, the yield stress $k$ is dependent on the filtered strain rate and orthotropy direction measured in the real test. With the assumption of no sudden changes in the orthotropy, the associated flow rule is used within this new material model.

\subsection{FE-Model}

In present work the new developed material model is used and validated by the tested results. The orthotropic visco-elastic properties, obtained from test results (see Table 1) are used, to model the orthotropic-visco-elasticity. During the loading phase, a precise modeling of the elastic properties is important to accurately predict the stress response of the entire model since all elements are participating in this mechanical region.

Figure 13 shows the three visco-plastic hardening curves for the MD direction obtained by the test carried out during this study and the DD direction result curves taken from Sahraei [17]. The engineering stress vs. engineering strain curves in MD direction are fitted to the Swift and Voce equations [31] and extrapolated to $100 \%$ strain, using an interpolation function as described in Bulla [16]. Figure 14 shows the FE results of the material behavior in MD direction. It can be seen that after the first localization occurs, the localized area remains at the same group of elements. These elements are further extending whereas the neighboring elements remain at the strain level, they had before the localization started. For these material curves (shown in Figure 13, left side) the slope of the true stress vs. true plastic strain curve is decreasing, which means, the material will not become stable back again.
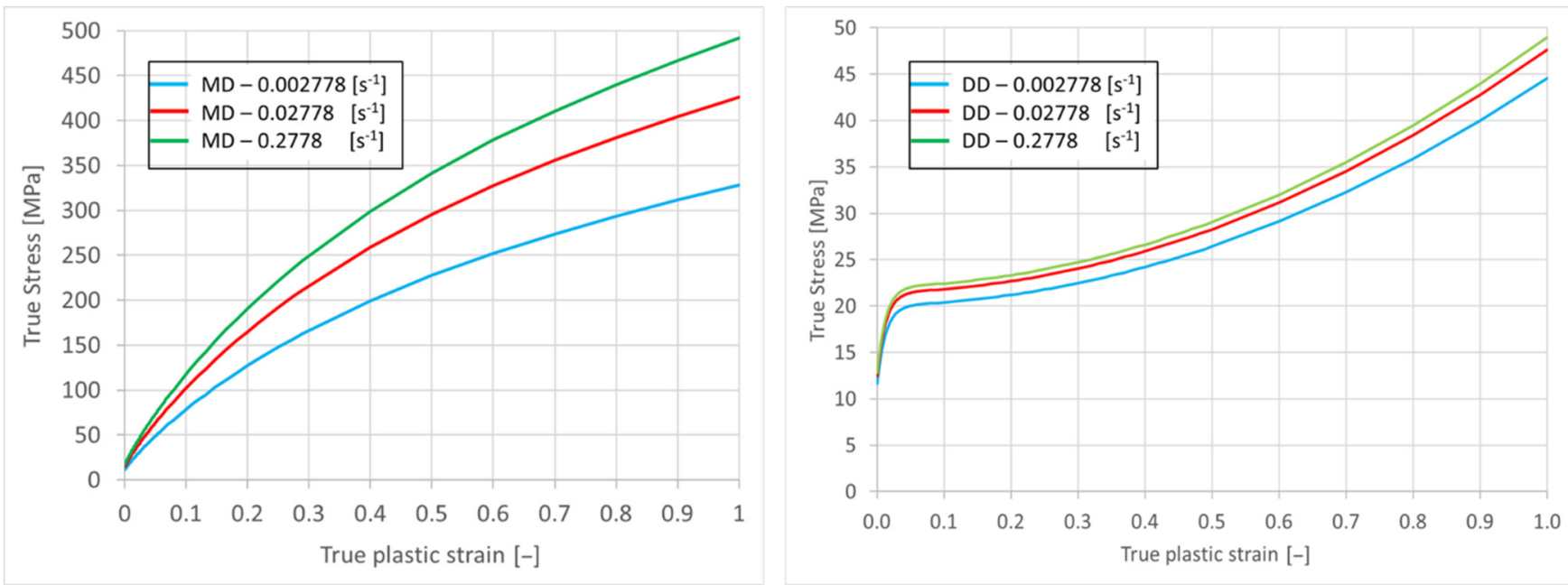

Figure 13. Strain rate dependent, orthotropic, hardening true stress vs. true plastic strain curves fitted to test results for MD $\left(0^{\circ}\right)$ direction (left side) and derived from tests provided in $\mathrm{DD}\left(45^{\circ}\right)$ direction (right side). 


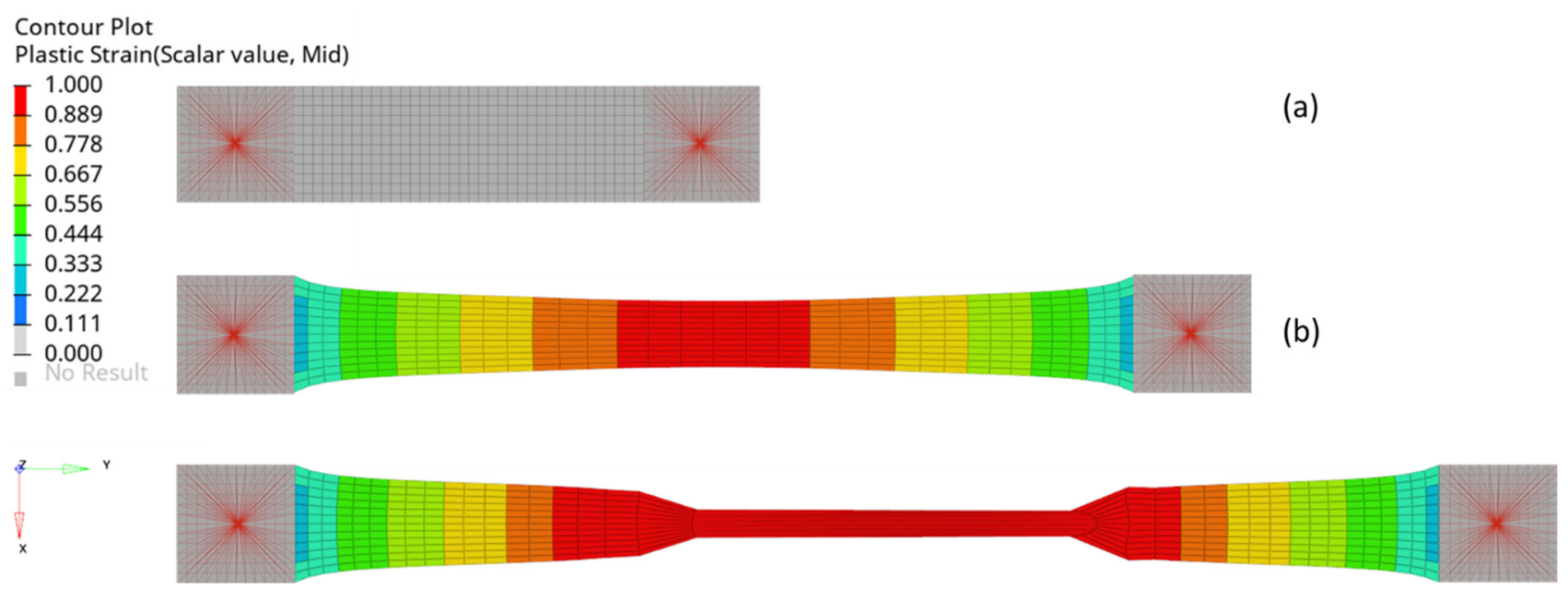

Figure 14. FE results showing the loading phases in the MD direction at initial stage (a), short before the first localization occurs (b) and further development of the total elongation (c).

Figure 15 shows the loading direction in the TD direction. As it can be seen in the hardening curve (Figure 13 right side), the slope decreases until $11 \%$ plastic strain and then increases again, which results in stabilization of the material.

Contour Plot

Plastic Strain(Scalar value, Mid)

1.000

0.889

0.778

- 0.667

$-0.556$

0.444

0.333

0.222

0.111

- 0.000
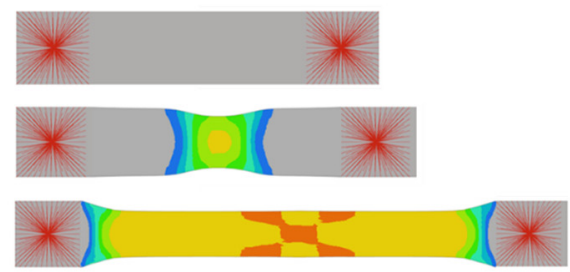

$\Rightarrow$ (a)

(b)

(c)

(d)

Figure 15. FE results showing the loading phases in the TD direction at initial stage (a), after first localization occurs (b), then proceeding through the specimen (c) and shortly before failure (d).

For materials with such hardening curves, the material becomes unstable as soon as the 1st derivative decreases and undergoes the hardening true-stress-strain curve. Then, the first localization can occur (Figure 15b) and become stable again. During further loading (Figure 15c) the material stiffness increases, and the first derivative raises above the true-stress-strain hardening curve. The material becomes stable again and localized strain occurs in another area (Figure 15d) during further loading of the structure. This numerical behavior, which can be simulated only with a sufficient complex material model, is also observed in real tests (Figure 12). Figure 16 shows the corresponding force vs. displacement simulation result curves. The influence of the strain rate dependent Young's moduli (see Table 1) is clearly visible (Figure 16, right side).

The simulations were conducted with the explicit FEA solver Radioss (version 2021) by Altair Engineering Inc. (1820 E. Big Beaver Rd., Troy MI 48083, USA), on a Windows64 computer using four Intel i7-6820 CPUs at $2.7 \mathrm{GHz}$ with 32GB RAM. The material model was developed in FORTRAN and linked to the FEA solver as a dynamic linked library (dll) compiled using the freeware MinGW-W64 project with a gcc 7.2.0 compiler [32]. The developed validation models were meshed using 4-node shell elements with a mesh size of $1 \times 1 \mathrm{~mm}$ and a defined thickness of $0.025 \mathrm{~mm}$. 

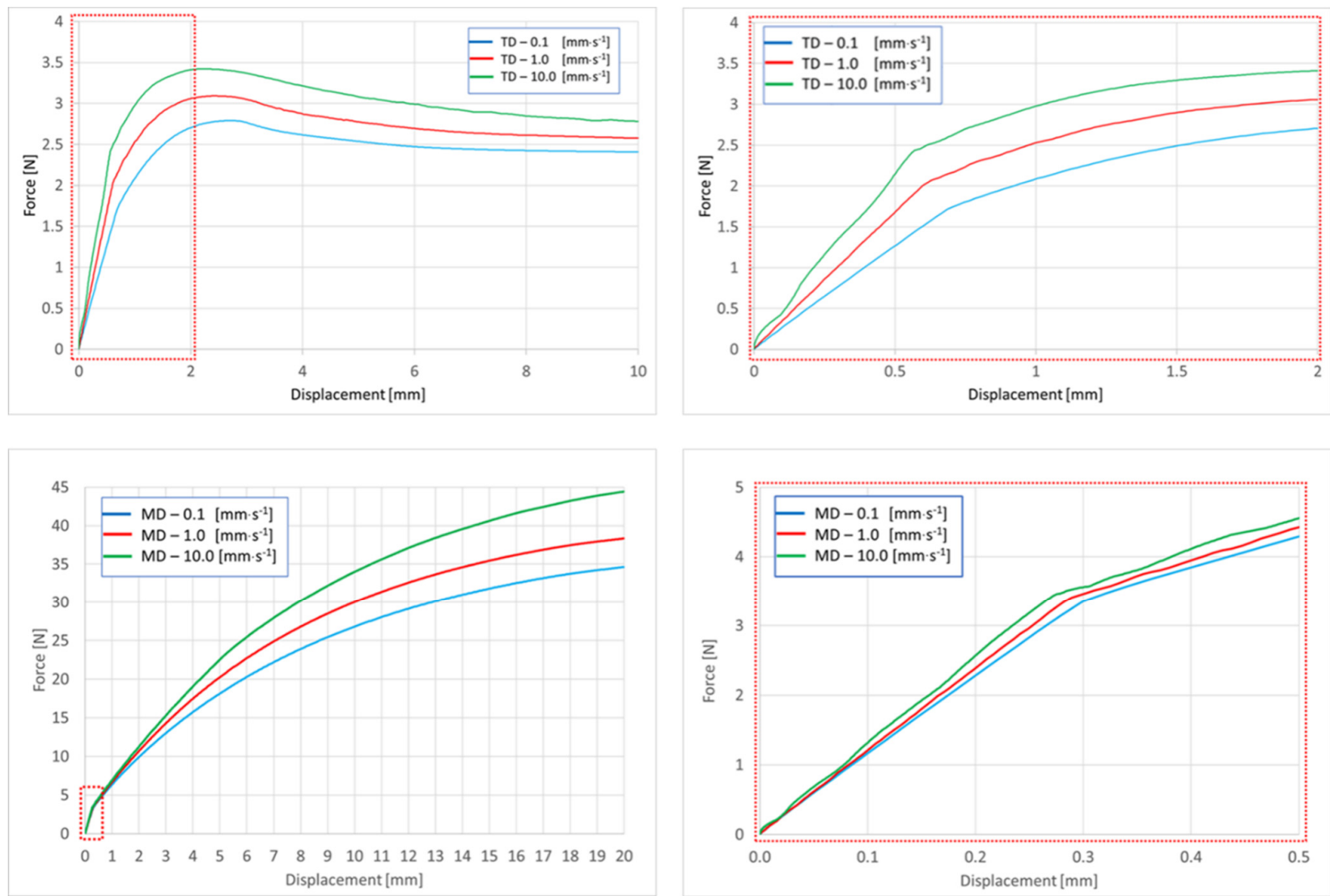

(b)

Figure 16. Force vs. displacement curves from simulations for different velocities. (a) load in TD, (b) load in MD.

\section{Discussion}

The objective of the presented work was the development of a finite element material model, for nonlinear, structural CAE simulation and predicting the mechanical behavior of a PE separator material under dynamic and high mechanical load, used for the prediction of stiffness and failure in Li-ion batteries. Nevertheless, our focus so far is set on crashworthiness analysis where batteries undergo very complicated state of deformation where bending plays an important role. Therefore, we set our focus on tensile loading until fracture for the separators.

Based on the real test results, performed with different velocities and different orientations of the specimen, a novel material model was developed. It considers the visco-elastic orthotropic, visco-plastic orthotropic behavior under high mechanical loadings. The developed FE material model accounts for the strain-rate effect in elastic loading phase and different material orientations, as well as the different elasto-plastic-orthotropic behavior in the plastic material domain, which was measured in the real tests. Within the material model, the Von Mises potential was used, which is widely used in the industry and suitable for modeling elasto-plastic materials. For material behavior characterization the only necessary information was the results from real tests in the three directions (MD, DD, TD), using a simple tension test under different loading velocities. Microscopic investigation of the battery separator after high mechanical loading along the MD and TD directions are published by Zhang [33]. Once the numerical material reaches instability, a further consideration of damage propagation and failure must be considered.

Compared to existing orthotropic material models, as developed by Hill or Barlat [34,35], the modeling is much easier due to the fact, that the orthogonal directions are obtained directly by using the real tests as input for this model. It is also possible to apply the Hill or Barlat yield surface if further studies show this need. 


\section{Conclusions and Outlook}

Within this work, our novel material model and the developed FE model succeeded in predicting the test for all three directions (MD, DD, TD) with different velocities in the linear elastic as well as the plastic domain within a range of $5 \%$. This lies within the scatter range of the tested specimen. For predicting the damage during this dynamic and high mechanical load, a suited failure model should be used in addition to the material model, as proposed by Bulla [16].

This should be useful in the design process of batteries and applications that contain batteries and will serve as an important new computational tool for assessing the safety of lithium-ion batteries against high mechanical loading and crashworthiness. The material model will be implemented in the commercial FE solver Altair Radioss and will thus be available for practical application in e-mobility simulation in near future. For porous polymers such as separators, pore orientation and connectivity affect their effective mechanical properties and performance in a battery, too [36]. However, this is the topic of further investigation and the usage of an extended model.

Author Contributions: Conceptualization, M.B., S.K. and E.S.; Formal analysis, S.K.; Methodology, M.B. and E.S.; Resources, S.K. and E.S.; Software, M.B.; Supervision, S.K. and E.S.; Validation, M.B., S.K. and E.S.; Visualization, M.B.; Writing-original draft, M.B. All authors have read and agreed to the published version of the manuscript.

Funding: This research received no external funding.

Institutional Review Board Statement: Not applicable.

Informed Consent Statement: Not applicable.

Acknowledgments: The authors would like to thank to Boston Powers for providing the isolator materials.

Conflicts of Interest: The authors declare no conflict of interest.

\section{References}

1. FAA Statement on Samsung Galaxy Note 7 Devices. Available online: https: / /www.faa.gov/news/updates/?newsId=86424 (accessed on 27 March 2020).

2. Liu, L.; Feng, X.; Rahe, C.; Li, W.; Lu, L.; He, X.; Sauer, D.U.; Ouyang, M. Internal short circuit evaluation and corresponding failure mode analysis for lithium-ion batteries. J. Energy Chem. 2021, 61, 269. [CrossRef]

3. Campusplastics-A Material Information System for the Plastics Industry. Available online: https://www.campusplastics.com/ (accessed on 1 October 2020).

4. Needleman, A. Plastic Strain Localization in Metals. Integr. Mater. Process. Prod. Design. 1999, 59-70. Available online: https:/ / www.researchgate.net/publication/288971313_Plastic_strain_localization_in_metals (accessed on 1 October 2020).

5. Norm ISO 527-1: 2019-Plastics-Determination of Tensile Properties. Available online: https://www.iso.org/standard/75824. html (accessed on 13 February 2020).

6. Michael, J. Characterization and Modelling of Nonreinforced Thermoplastic Polymers for Numerical Simulation of Crashworthiness; Fraunhofer IRB Verlag: Freiburg, Germany, 2004; ISBN 3-8167-6339-1.

7. Hopkinson, J. On the Rupture of Iron Wire by a Blow; Cambridge University: Cambridge, UK, 1901.

8. Gebbeken, N. On the Investigation of the Linear Load-Bearing Behaviour of Fiber Reinforced Plastic Structures Using Numerical Methods; Universität der Bundeswehr: Munich, Germany, 1996.

9. Ebewele, R.O. Polymer Science and Technology; CRC Press: Benin City, Nigeria, 1996.

10. Walley, S.M.; Field, J.E. Strain rate sensitivity of polymers in compression from low to high rates. DYMATJ. 1994, 1, $211-227$.

11. Carnella, J.; Liu, X.; Leng, C.Z.; Sinko, P.D.; Gor, G.Y.; Arnold, C.B. Mechanical Properties of a Battery Separator under Compression and Tension. J. Electrochem. Soc. 2014, 161, F3117.

12. Junginger, M.; Werner, H.; Passmann, R.; Thoma, K.; Hiermaier, S. Characterization and modelling thermoplastic polymers. In Proceedings of the ABAQUS Users Meeting, Freiburg, Germany, 24-25 September 2001.

13. Pfeiffer, M.; Kolling, S. A constitutive model for the anisotropic elastic-Plastic deformation of paper and paperboard. J. Solids Struct. 2019, 39, 4053-4071.

14. Zhu, L.; Xia, Y.; Liu, Y.; Ge, Y.; Wang, L.; Zhang, L. Extending a Homogenized Model for Characterizing Multidirectional Jellyroll Failure in Prismatic Lithium-Ion Batteries. Energies 2021, 14, 3444. [CrossRef] 
15. Li, A.; Yuen, A.C.Y.; Wang, W.; De Cachinho Cordeiro, I.M.; Wang, C.; Chen, T.B.Y.; Zhang, J.; Chan, Q.N.; Yeoh, G.H. A Review on Lithium-Ion Battery Separators towards Enhanced Safety Performances and Modelling Approaches. Molecules 2021, $26,478$. [CrossRef]

16. Bulla, M.; Kolling, S.; Sahraei, E. An Experimental and Computational Study on the Orthotropic Failure of Separators for Lithium-Ion Batteries. Energies 2020, 13, 4399. [CrossRef]

17. Zhang, X.; Sahraei, E.; Kai, W. Deformation and failure characteristics of four types of lithium-ion battery separators. J. Power Sources 2016, 327, 693-791. [CrossRef]

18. Altair Engineering, Inc. RADIOSS Manual. Available online: www.altairhyperworks.com (accessed on 17 March 2020).

19. Livermore Software. Technology Corporation, LS-Dyna Keyword User's Manual Volume I11/27/14 (r:5869); LSTC Corp.: Livermore, CA, USA, 2014.

20. Smith, M. ABAQUS/Explicit, User's Manual, Version 6.9. Available online: http://130.149.89.49:2080/v6.8/books/usi/default htm?startat=pt01.html (accessed on 28 July 2021).

21. Chou, Y.L. Statistical Analysis, Holt International; Section 17.9; Holt, Rinehart and Winston of Canada Ltd.: Toronto, ON, Canada, 1975; ISBN 0-03-089422-0.

22. G'Sell, C.; Jonas, J. Determination of the plastic behaviour of solid polymers at constant true strain rat. J. Mater. Sci. 1979, 14, 583-591. [CrossRef]

23. Belytschko, T.; Lin, J.I. Eigenvalues and stable time step for the bilinear midlin plate element. J. Numer. Methods Eng. 1985, 21, 1729-1945. [CrossRef]

24. Altair Engineering, Inc. RADIOSS Theory Manual. Available online: www.altairhyperworks.com (accessed on 17 March 2020).

25. Drucker, D.C. A Definition of a Stable Inelastic Material; Technical Report No.2; Brown University: Providence, RI, USA, 1957.

26. Bergström, J. Mechanics of Solid Polymers; Matthew Deans: Moffett Field, CA, USA, 2015.

27. Boyce, M.C.; Parks, D.M.; Argon, A.S. Large inelastic Deformation of Glossy polymers. Part I: Rate Dependant Constitutive Model. Mech. Mater. 1988, 7, 15-33. [CrossRef]

28. Argon, A.S. A Theory for the low-temperature plastic deformation of glossy polymers. Phylosophical Mag. 1973, 28, 839-865. [CrossRef]

29. Zerilli, F.J.; Armstrong, R.W. Thermal activation based constitutive equations for polymers. J. Phys. IV Fr. 2000, 10, Pr9-3-Pr9-8. [CrossRef]

30. Mises, R. Mechanik der festen Körper im plastischen deformablen Zustand. Nachricht von der Königlichen Gesellschaft der Wissenschaften zu Göttingen. Math. Kl. 1913, 582-592.

31. Roth, C.; Mohr, D. Effect of strain rate on ductile fracture initiation in advanced high strength steel sheets: Experiments and modeling. J. Plast. 2014, 56, 19-44. [CrossRef]

32. MinGW Minimalist GNU for Windows. Available online: http:/ /www.mingw.org/ (accessed on 17 October 2018).

33. Zhang, X.; Sahraei, E.; Wang, K. Li-ion Battery Separators, Mechanical Integrity and Failure Mechanisms Leading to Soft and Hard Internal Shorts. Sci. Rep. 2016, 6, 32578. [CrossRef] [PubMed]

34. Hill, R. A theory of the yielding and plastic flow of anisotropic metals. Proc. R. Soc. Lond. A Math. Phys. Eng. Sci. 1948, 193, 281-297. [CrossRef]

35. Barlat, F.; Lian, J. Plastic behaviour and stretchability of sheet metals. Part I: A yield function for orthotropic sheets under plane stress conditions. Int. J. Plast. 1989, 5, 51-66. [CrossRef]

36. Lagadec, M.F.; Zahn, R.; Wood, V. Designing Polyolefin Separators to Minimize the Impact of Local Compressive Stresses on Lithium Ion Battery Performance. J. Electrochem. Soc. 2018, 165, A1829. [CrossRef] 